\title{
Exploration of reduced graphene oxide microparticles as electrocatalytic materials in vanadium redox flow batteries
}

\author{
Amira Alazmi ${ }^{\mathrm{a}, \mathrm{b}}$, Charles Tai-Chieh Wan ${ }^{\mathrm{b}}$, Pedro M. F. J. Costa ${ }^{\mathrm{c}}$, and Fikile R. Brushett ${ }^{\mathrm{b},{ }^{*}}$ \\ a Department of Chemistry, University Colleges at Nairiyah, University of Hafr Albatin, Nairiyah 31981, Saudi \\ Arabia \\ $b \quad$ Department of Chemical Engineering, Massachusetts Institute of Technology, Cambridge, MA, 02139, United \\ States of America \\ c King Abdullah University of Science and Technology, Physical Sciences and Engineering Division, Thuwal \\ 23955-6900, Saudi Arabia \\ * Corresponding Author Email Address: brushett@mit.edu
}

\begin{abstract}
Augmenting reaction rates on porous carbon electrodes is critical for reducing the cost of allvanadium redox flow batteries (VRFBs). To this end, reduced graphene oxide (rGO) based carbons hold promise, demonstrating high specific surface area, chemomechanical stability, and electrochemical activity. While initial efforts have shown that rGOs can enhance VRFB performance, the range of unique processing conditions leads to a collection of materials with disparate elemental composition and porous structure, thus obscuring performance-determining characteristics behind redox reactions and frustrating the development of generalizable design principles. Here, we generate rGO electrocatalysts of nearly identical chemical composition but different textures (i.e., surface area and pore structure) by varying the drying step in the graphene synthesis (i.e., vacuum-drying vs. carbon dioxide critical point drying). We apply spectroscopic and electrochemical techniques on the synthesized rGOs, observing a three-fold increase in BET surface area using critical point drying. We subsequently decorate carbon felt electrodes - both pristine and thermally activated - with rGO microparticles via a flow deposition procedure, and evaluate their performance and durability in a VRFB cell. The synthesis approach and findings described in this work inform and complement efforts to advance the material science and engineering of rGO electrocatalysts.
\end{abstract}

Keywords: Reduced graphene oxide, passive flow deposition, carbon felt, electrocatalyst, vanadium redox flow battery 


\section{Introduction}

Energy storage technologies are poised to play an integral role in the efficient and reliable delivery of electricity from low-cost, sustainable, but intermittent renewable energy sources. ${ }^{[1-4]}$ Redox flow batteries (RFBs) hold particular promise for long-duration energy storage applications due to their independent power and energy scaling, modular design, and long service life. ${ }^{[5-6]}$ The current state-of-the-art system is the vanadium redox flow battery (VRFB) which utilizes four stable and soluble oxidation states of vanadium dissolved in an aqueous acidic electrolyte, specifically $\mathrm{V}(\mathrm{II}) / \mathrm{V}(\mathrm{III})$ and $\mathrm{V}(\mathrm{IV}) / \mathrm{V}(\mathrm{V})$ as the negative and positive redox couples, respectively. ${ }^{[7-11]}$ The use of the same parent compound greatly simplifies system maintenance, as capacity lost due to species crossover through semi-permeable membranes can be recovered through periodic electrolyte rebalancing events. However, while contemporary VRFBs have experienced modest commercial success, ${ }^{[12]}$ broad adoption has been hindered by prohibitive costs, ${ }^{[11,13]}$ prompting research efforts focused on novel electrolyte formulations ${ }^{[14]}$ and advanced reactor designs. ${ }^{[15-19]}$

Opportunities for cost-effective VRFBs have spurred the development of more compact and higher-power electrochemical stacks, which are comprised of multiple flow cells arranged in series and/or parallel. ${ }^{[20]}$ Integral to these advancements is the need to improve the performance of the porous carbon electrodes, a core component of the flow cell which simultaneously provides active sites for the electrochemical reactions, conducts electrons and heat, and distributes electrolyte throughout the reactive volume. As such, the electrode surface chemistry and microstructure influence electrochemical performance through kinetic, ohmic, and mass transport resistances, and fluid dynamics through hydraulic resistance. Historically, carbon felts (CFs), derived from polyacryonitrile or Rayon, have been used as electrodes in RFBs due to their three dimensional structure, electrical conductivity, chemical stability in acidic electrolytes, and mechanical 
flexibility/compressibility. ${ }^{[13,21-25]}$ However, vanadium redox reactions are sluggish (standard heterogeneous rate constant, $\left.\mathrm{k}^{0} \sim \mathrm{O}\left(<10^{-5} \mathrm{~cm} \mathrm{~s}^{-1}\right)\right)$ on unmodified carbon surfaces, ${ }^{[26]}$ hampering cell power output, and incentivizing strategies to enhance reaction rates. ${ }^{[27]}$

To address this challenge, post-process modifications of porous carbon electrodes targeting the augmentation of electrochemically active surface area (ECSA) and/or the alteration of surface chemistry have been extensively investigated as a means of increasing electrocatalytic performance. Treatments of the carbon electrodes can be broadly categorized into subtractive or additive methods. In subtractive methods, the carbon electrode is roughened via thermal / chemical, ${ }^{[28-29]}$ plasma or microwave, ${ }^{[30]}$ or electrochemical ${ }^{[31]}$ routes, thereby increasing active site density, and potentially functionalizing the electrode surface with desirable catalytic groups. In additive methods, the fiber bed is leveraged as a substrate to deposit micro- or nanoscale particles ${ }^{[32-34]}$ or structures ${ }^{[35-38]}$ increasing ECSA and providing active sites that promote the vanadium reactions.

To this end, the deposition of electrocatalytic particles into the porous electrodes presents an opportunity for performance improvement and, potentially, cost reduction. ${ }^{[6]}$ Of the numerous candidates, graphene materials have drawn particular attention because of their high specific surface area, high electrical conductivity, chemomechanical stability, and electrochemical activity. ${ }^{[39]}$ Despite the unique favorable properties offered by graphene, typical synthesis routes for high quality (i.e., monolayer) graphene via mechanical cleavage of highly oriented pyrolytic graphite, epitaxial growth on silicon carbide, or chemical vapor deposition are limited by throughput and/or cost, thus complicating production at scale. Solution-based processes may represent a more practical and higher-yield approach, wherein graphite is initially oxidized to graphite oxide (GO), exfoliated into GO sheets, and subsequently reduced to form reduced 
graphene oxide (rGO) sheets. However, increased product yields are realized at the expense of quality, thus motivating research efforts to improve the morphology and surface chemistry of rGO material through optimization of the agents and process step conditions in the synthesis route. ${ }^{[20,}$ 40-43]

Towards electrochemical applications, high surface area graphene has been demonstrated to promote ionic adsorption and to improve the electrode performance for VRFBs, oxygen evolution from water, and remediation of environmental pollutants. ${ }^{[6,44-45]}$ A growing body of work has focused on leveraging the properties of graphene-based materials in RFBs, ${ }^{[20,46]}$ investigating various elemental dopings ${ }^{[32,47-48]}$ and porous structures, ${ }^{[49-50]}$ in combination with different cell chemistries (i.e., all-iron ${ }^{[51]}$ and all-vanadium ${ }^{[12]}$ ). However, the range in unique processing conditions lead to rGOs of diverse elemental composition and porous structure, which, in turn, obfuscates the key material characteristics that promote reaction rates. Hence, there is a need to continue exploring structure-performance relationships for $\mathrm{rGO}$ microparticles within RFBs to understand how features such as surface texture impact electrode and cell performance.

Here, we describe an approach to synthesizing rGO electrocatalysts of different textures (i.e., surface area and pore structure) but nearly identical composition and compare their respective performances within a VRFB cell. Specifically, we assess the relative importance of the postsynthesis step (i.e., drying) in the graphene synthesis which controls the surface area and mesoporosity of the resultant powder. Notably, through process refinement, we observe a more than three-fold increase in surface area as compared to hydrothermally-reduced GO, $364 \mathrm{~m}^{2} \mathrm{~g}^{-1} \mathrm{vs}$. $<100 \mathrm{~m}^{2} \mathrm{~g}^{-1}$, as well as broader mesoporous pore size distribution ranging from $2-90 \mathrm{~nm}$ with a dominant size of $\sim 20 \mathrm{~nm}$. We then adhere these high surface area micromaterials to porous carbon felts - both pristine and thermally activated - via a flow deposition method compatible with 
existing cell architectures and evaluate the performance and durability of the rGO-decorated felt electrodes in a small-scale VRFB cell (Figure 1). We anticipate that the strategies described in this work will prove broadly applicable to electrode engineering efforts in forced-convection based electrochemical technologies.

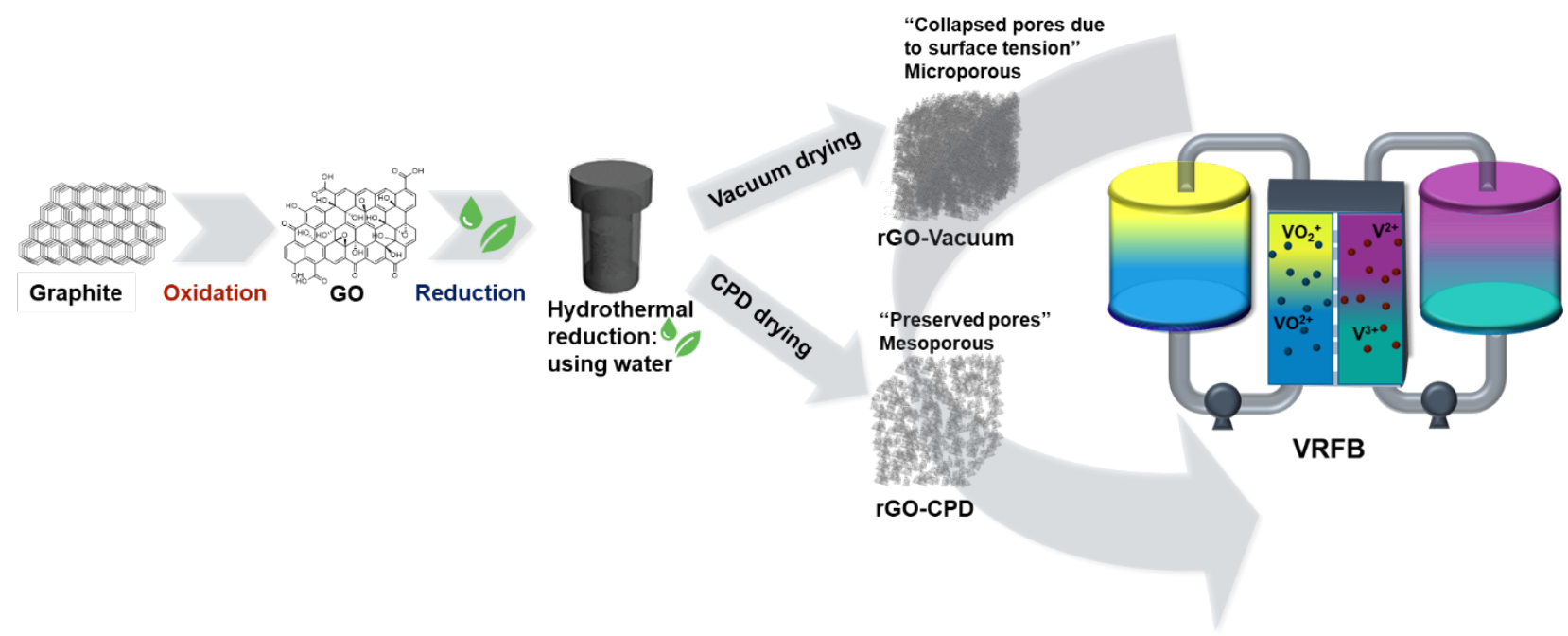

Figure 1. Scheme of the work presented in this study: Graphite is oxidized and exfoliated using the improved Hummers' method, ${ }^{[40,52]}$ and subsequently reduced via a sustainable hydrothermal reduction method using water as the solvent to produce rGO. The post-synthesis drying method enables control over the resulting surface area and pore structure of the rGO microparticles. The electrocatalysts are flow-deposited on carbon felt electrodes and implemented into a VRFB single cell to evaluate their impact on electrochemical performance. 


\section{Experimental}

Materials synthesis: Graphite powder (99\%, crystalline, 325 mesh, Alfa Aesar) was oxidized and exfoliated using the improved Hummers' method, as described elsewhere. ${ }^{[40,52]}$ The graphene oxide (GO) powder was subsequently dried, either in vacuum (Thermo Scientific Lindberg/Blue M Vacuum Oven) at $60^{\circ} \mathrm{C}$ for $24 \mathrm{~h}$ or by critical point drying (CPD) in a Leica EM CPD300. The dried powders were then hydrothermally reduced. Typically, $100 \mathrm{mg}$ of GO powder was dispersed in $40 \mathrm{~mL}$ of deionized (DI) water (ca. 18.2 M , Millipore) and stirred for $24 \mathrm{~h}$ to form a dispersion. Then, the mixture was transferred to a $50 \mathrm{~mL}$ Teflon-lined autoclave and kept in an oven (Thermo Scientific Lindberg/Blue M Vacuum Oven) at $180^{\circ} \mathrm{C}$ for $24 \mathrm{~h}$. Finally, the rGO powders were dried in a similar manner to the parent GO powders and designated as rGO-vacuum and rGO-CPD, named accordingly based on the drying method. ${ }^{[53]}$

Materials characterization: The structural analysis was performed by powder X-ray diffraction (XRD) on a Bruker D8 ADVANCE and using a $\mathrm{Cu} \mathrm{K}$ radiation $(\lambda=1.54 \AA)$ at a scan rate of $5^{\circ}$ $\min ^{-1}$ and increments of $0.02^{\circ}$. Scanning electron microscopy (SEM) of rGO particles was performed on a FEI Quanta 600, operated at $4 \mathrm{kV}$. Gas adsorption-desorption measurements were conducted with $\mathrm{N}_{2}$ at $77 \mathrm{~K}$ using a Micromeritics ASAP 2420 instrument. Prior to the analysis, the samples were degassed under vacuum at $80{ }^{\circ} \mathrm{C}$ for at least $12 \mathrm{~h}$. The specific surface area was calculated using the Brunauer-Emmett-Teller (BET) method. The pore size distribution analysis in the mesopore range was performed using the Barrett-Joyner-Halenda (BJH) formalism applied to the isotherm adsorption branch, and the full micro-meso pore size distribution was calculated using a density functional theory (DFT) model assuming slit pores with the Micromeritics ${ }^{\circledR}$ MicroActive Interactive data analysis software. ${ }^{[54]}$ X-ray photoelectron spectroscopy (XPS) studies were performed in a Kratos Axis Ultra DLD spectrometer equipped with a monochromatic 
Al Ka X-ray source $(\mathrm{h} v=1486.6 \mathrm{eV})$ operating at $150 \mathrm{~W}$, a multi-channel plate and delay line detector under a vacuum of $\sim 10^{-9}$ mbar. Survey and high-resolution XPS spectra were collected at fixed analyzer pass energies of $160 \mathrm{eV}$ and $20 \mathrm{eV}$, respectively. Samples were mounted in floating mode in order to avoid differential charging. Binding energies were referenced to the $\mathrm{sp}^{2}$ hybridized $(\mathrm{C}=\mathrm{C})$ carbon for the $\mathrm{C} 1 \mathrm{~s}$ peak set at $284.4 \mathrm{eV}$.

Thermal pretreatment of carbon paper electrodes: Sigracet SGL GFA6EA felt electrodes (Fuel Cell Store, College Station, Texas, USA) were thermally oxidized under air in a Barnstead Thermolyne Type 47900 muffle furnace by ramping at a rate of $20{ }^{\circ} \mathrm{C} \mathrm{min}{ }^{-1}$ from room temperature to $450^{\circ} \mathrm{C}$, holding for $6 \mathrm{~h}$, and cooling down naturally to room temperature. During the thermal treatment, the electrodes were placed on aluminum foil to prevent contamination and to prevent individual electrodes from overlapping. The electrodes were stored in sealed plastic containers under air.

Electrode morphology characterization: The carbon felt porous scaffold and deposited electrode morphologies were characterized using SEM. Measurements were performed using a ZEISS MERLIN HR-SEM (Jena, Germany) with an electron energy of $3 \mathrm{keV}$, an aperture of $30 \mu \mathrm{m}$, and a gun-to-sample distance of ca. $5 \mu \mathrm{m}$. The samples were affixed to the stage with double-sided conductive carbon tape (Ted Pella Inc.).

Evaluation of $r G O$ performance as an electrocatalyst in flow cell testing: Electrochemical measurements were performed in a $2.55 \mathrm{~cm}^{2}$ zero-gap flow cell architecture ${ }^{[55]}$ with interdigitated flow fields, a Nafion ${ }^{\mathrm{TM}} 212$ membrane (FuelCellStore, $50.8 \mu \mathrm{m}$ nominal thickness) presoaked in $3 \mathrm{M} \mathrm{H}_{2} \mathrm{SO}_{4}$ for $>24 \mathrm{~h}$, and carbon felt electrodes (SIGRACELL® GFA 6 EA, $6 \mathrm{~mm}$ thick), with

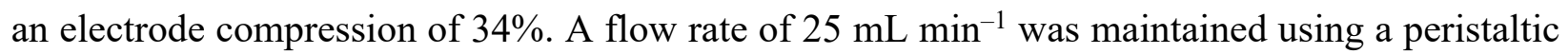
pump (Masterflex L/Series model) and Norprene tubing (Masterflex L/S 16). All flow cell 
experiments, with an exception of electrochemical impedance spectroscopy (EIS) measurements, were performed using an Arbin battery tester (FBTS-8). EIS was performed using a VMP3 BioLogic potentiostat (Bio-Logic USA, Knoxville, TN).

Prior to cell testing, the VRFB electrolyte was prepared by electrolysis. A potentiostatic precharge step was used, wherein the cell was held at a potential of $1.8 \mathrm{~V}$ until the current dropped below $10 \mathrm{~mA}$ (ca. $3.9 \mathrm{~mA} \mathrm{~cm}{ }^{-2}$ ). During this step, the positive electrolyte was oxidized from $\mathrm{VO}^{2+}$ $(\mathrm{V}(\mathrm{IV}))$ to $\mathrm{VO}_{2}^{+}(\mathrm{V}(\mathrm{V}))$ and the negative electrolyte was reduced from $\mathrm{VO}^{2+}(\mathrm{V}(\mathrm{IV}))$ to $\mathrm{V}^{3+}$ (V(III)). Subsequently, the $\mathrm{VO}_{2}{ }^{+}$solution was replaced with fresh $\mathrm{VO}^{2+}$ solution and the cell was galvanostatically charged, at $100 \mathrm{~mA} \mathrm{~cm}{ }^{-2}$, until the cell potential reached $1.8 \mathrm{~V}$. The cell was then galvanostatically discharged, at $100 \mathrm{~mA} \mathrm{~cm}^{-2}$, to $50 \% \mathrm{SOC}$ for subsequent electrochemical testing. Each electrolyte reservoir (PYREX ${ }^{\circledR}$ Media Bottles, Graduated, Corning ${ }^{\circledR}, 100 \mathrm{~mL}$ capacity) was actively purged with humidified nitrogen to prevent chemical oxidation of the redox couples via exposure to oxygen. For discharge polarization, rate study, and EIS measurements, the starting electrolyte in both reservoirs $\left(50 \mathrm{~mL}\right.$ in each) was $1.5 \mathrm{M} \mathrm{VOSO}_{4}\left(\mathrm{VO}^{2+}\right)$, from vanadium (IV) sulfate oxide hydrate (99.9\% metals basis, Alfa Aesar), in $2.6 \mathrm{M} \mathrm{H}_{2} \mathrm{SO}_{4}$. For the cycling stability test, lower active species concentrations and electrolyte volumes were selected to achieve more galvanostatic cycles while minimizing the effect of cell failure modes unrelated to electrode performance. Specifically, the starting electrolyte in both reservoirs $(25 \mathrm{~mL}$ each) was $1.0 \mathrm{M}$ $\mathrm{VOSO}_{4}\left(\mathrm{VO}^{2+}\right)$, from vanadium (IV) sulfate oxide hydrate, in $3.0 \mathrm{M} \mathrm{H}_{2} \mathrm{SO}_{4}$.

EIS was performed at open circuit potential and 50\% SOC to identify the kinetic, ohmic, and mass transport contributions to the total DC resistance of the flow cell. Frequencies from $1 \mathrm{MHz}$ to $10 \mathrm{mHz}$ were applied at 6 points per decade, and an average of 5 measures per frequency was recorded. The sinus amplitude was $10 \mathrm{mV}$. Upon completion of EIS, discharge polarization curves 
were obtained by discharging the cell for $30 \mathrm{~s}$ at current densities varying from 25 to $500 \mathrm{~mA} \mathrm{~cm}^{-2}$ in increments of $25 \mathrm{~mA} \mathrm{~cm}^{-2}$. Data were recorded every second, and data points from the last $15 \mathrm{~s}$ at each current density were used to quantify the degree of polarization to ensure the system was at steady state. After each discharge, the cell was returned to $50 \%$ SOC by charging at $100 \mathrm{~mA} \mathrm{~cm}^{-2}$ for a set time that ensured coulombic balance.

A rate study was conducted by varying current densities from 100 to $200 \mathrm{~mA} \mathrm{~cm}{ }^{-2}$ in increments of $50 \mathrm{~mA} \mathrm{~cm}^{-2}$. The flow cells were cycled 6 times at each current density, with the same current density used for charge and discharge. The cycling stability of the flow cells was evaluated via galvanostatic cycling at $100 \mathrm{~mA} \mathrm{~cm}^{-2}$ for 100 cycles (ca. 12.92 days). In both cases, cutoff cell voltages were set at $1.8 \mathrm{~V}$ for charge to avoid the parasitic oxygen evolution reaction and $0.8 \mathrm{~V}$ for discharge. Coulombic efficiency of the cell is calculated as the ratio of discharge time to charge time. Voltaic efficiency of the cell is calculated as the ratio of average discharge voltage to average charge voltage, and energy efficiency is calculated as the ratio of average discharge energy to average charge energy.

The impact of rGO for full-cell performance was assessed by flow depositing rGO onto the carbon felts using a previously published technique. ${ }^{[33-34]}$ In brief, $15 \mathrm{mg}$ of carbon was suspended and dispersed in $3 \mathrm{~mL}$ DI water and sonicated for at least $20 \mathrm{~min} .1 .5 \mathrm{~mL}$ of the resulting suspension was then pipetted into both electrolyte reservoirs and circulated for 1-2 days at a flow rate of $25 \mathrm{~mL} \mathrm{~min}^{-1}$ to ensure adherence of the rGO to the felt electrodes. We assume a high degree of rGO uptake into the felt electrode based on changes in the electrolyte color seen in previous work and because we did not observe visible deposits at the bottom of the reservoir tanks. ${ }^{[34]}$ Further, we hypothesize that the electrolyte is well-mixed by continuous circulation through the flow cell, preventing deposits from settling to the bottom of the reservoir. 


\section{Results and Discussion}

\subsection{Structural and chemical analyses of synthesized $r G O$}

We first compare the surface chemistry and topology of the rGO samples through a series of spectroscopy and characterization techniques. The morphologies of the two hydrothermal rGO samples studied (rGO-vacuum and rGO-CPD) are shown in Figure 2. Particle sizes range from 5 to $15 \mu \mathrm{m}$ for both rGO samples, as determined by SEM. Compared to the rGO-vacuum, the rGOCPD exhibits finer and more consistent separation of the corrugated basal planes, illustrating the impact of each drying method.
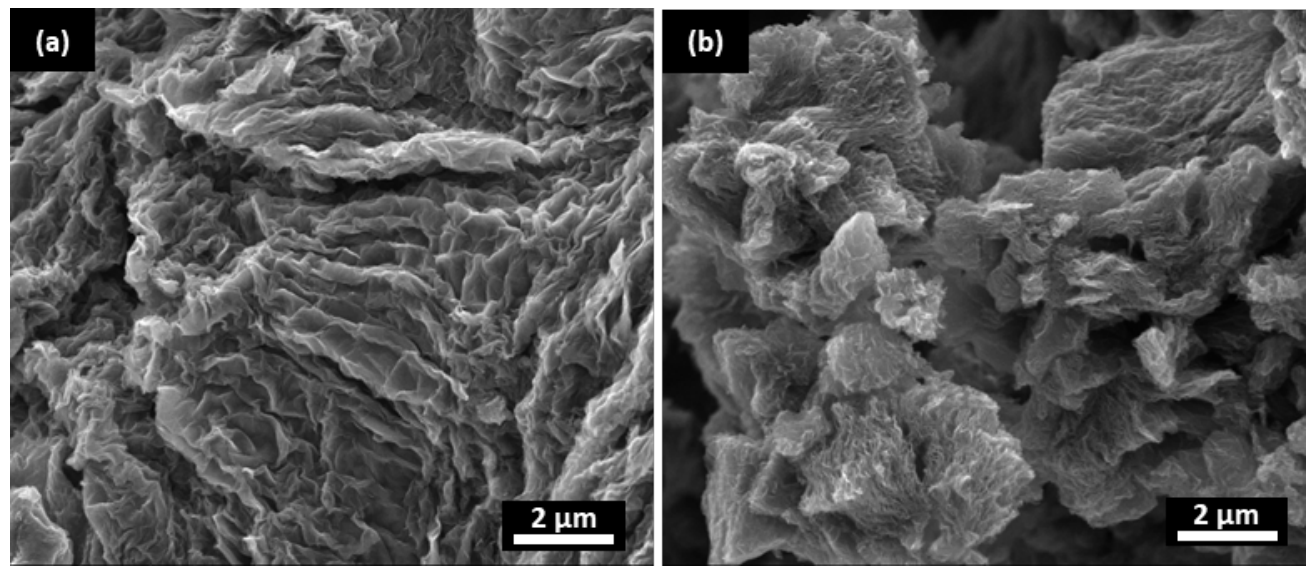

Figure 2. SEM images of rGO materials prepared by different post-synthesis process: (a) rGOvacuum; (b) rGO-CPD.

X-ray powder diffraction (XRD) and X-ray photoelectron spectroscopy (XPS) analyses enable comparison of the structure and surface chemistry of the rGOs samples. Figure 3 shows the XRD pattern; all samples display two diffraction peaks at $2 \theta=25^{\circ}$ and $43^{\circ}$, assigned to the (002) and (101) planes of graphite, respectively. ${ }^{[54]}$ The similarities between the intensity and placement of the peaks for the rGO-CPD and rGO-vacuum indicate that the crystallographic structure and physical properties are near identical. 


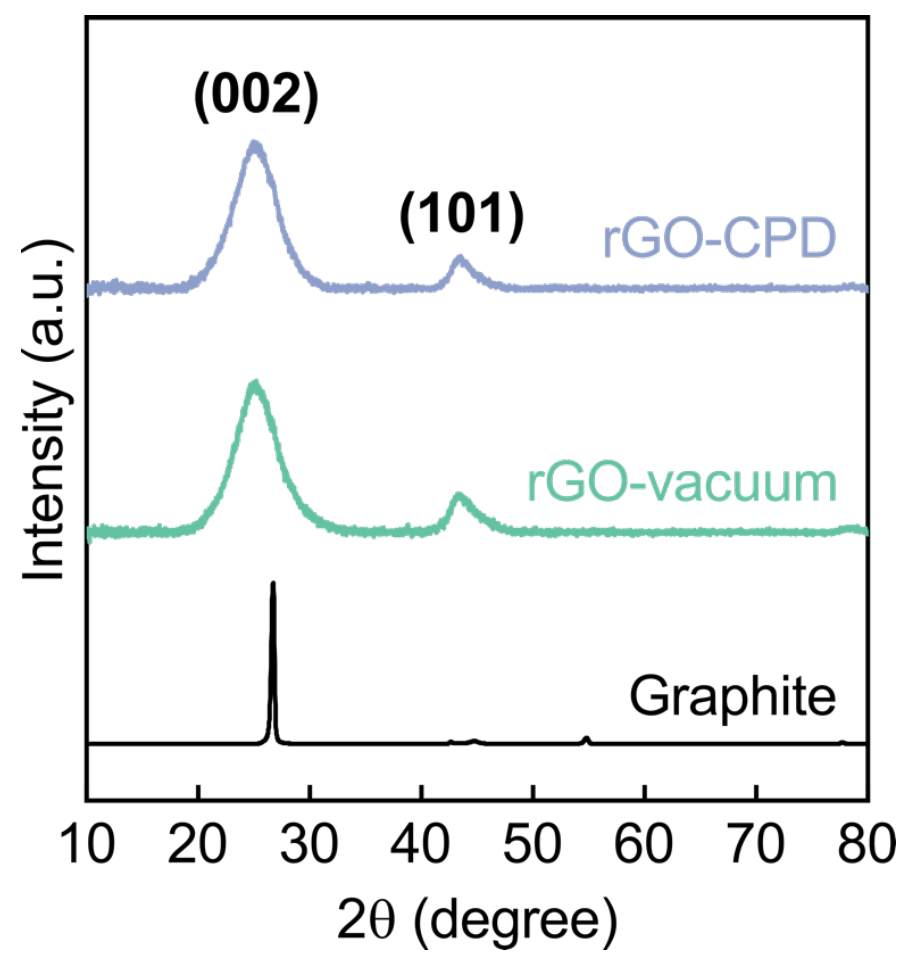

Figure 3. Powder XRD patterns of the graphite precursor, rGO-vacuum, and rGO-CPD samples.

High resolution XPS study of the C 1s peak further highlights the structural and chemical similarity of the rGOs (Figure 4). The deconvoluted high-resolution C 1s spectra for both rGOvacuum and $\mathrm{rGO}-\mathrm{CPD}$ show an intense peak of $\mathrm{C}=\mathrm{C}\left(\mathrm{sp}^{2}\right.$ arrangement) located at $284.4 \mathrm{eV}$. Besides the $\mathrm{C}=\mathrm{C}$ peak, the $\mathrm{C} 1 \mathrm{~s}$ spectrum deconvolution identifies five other bands: $\mathrm{sp}^{3}(285.3 \mathrm{eV})$, $\mathrm{C}-\mathrm{OH}(286.4 \mathrm{eV}), \mathrm{C}=\mathrm{O}(288.0 \mathrm{eV}), \mathrm{O}-\mathrm{C}=\mathrm{O}(288.9 \mathrm{eV})$, and the $\pi-\pi^{*}$ satellite peak $(290.8 \mathrm{eV})$. The relative concentration (atomic \%) of the components are calculated using CasaXPS software as: $\mathrm{C}=\mathrm{C} 65 \%, \mathrm{sp}^{3} 13 \%, \mathrm{C}-\mathrm{OH} 11 \%, \mathrm{C}=\mathrm{O} 5 \%, \mathrm{O}-\mathrm{C}=\mathrm{O} 3 \%$ and $\pi-\pi * 3 \%$. Hence, independent of the drying process used, the final materials exhibit comparable structure and surface chemistry. 

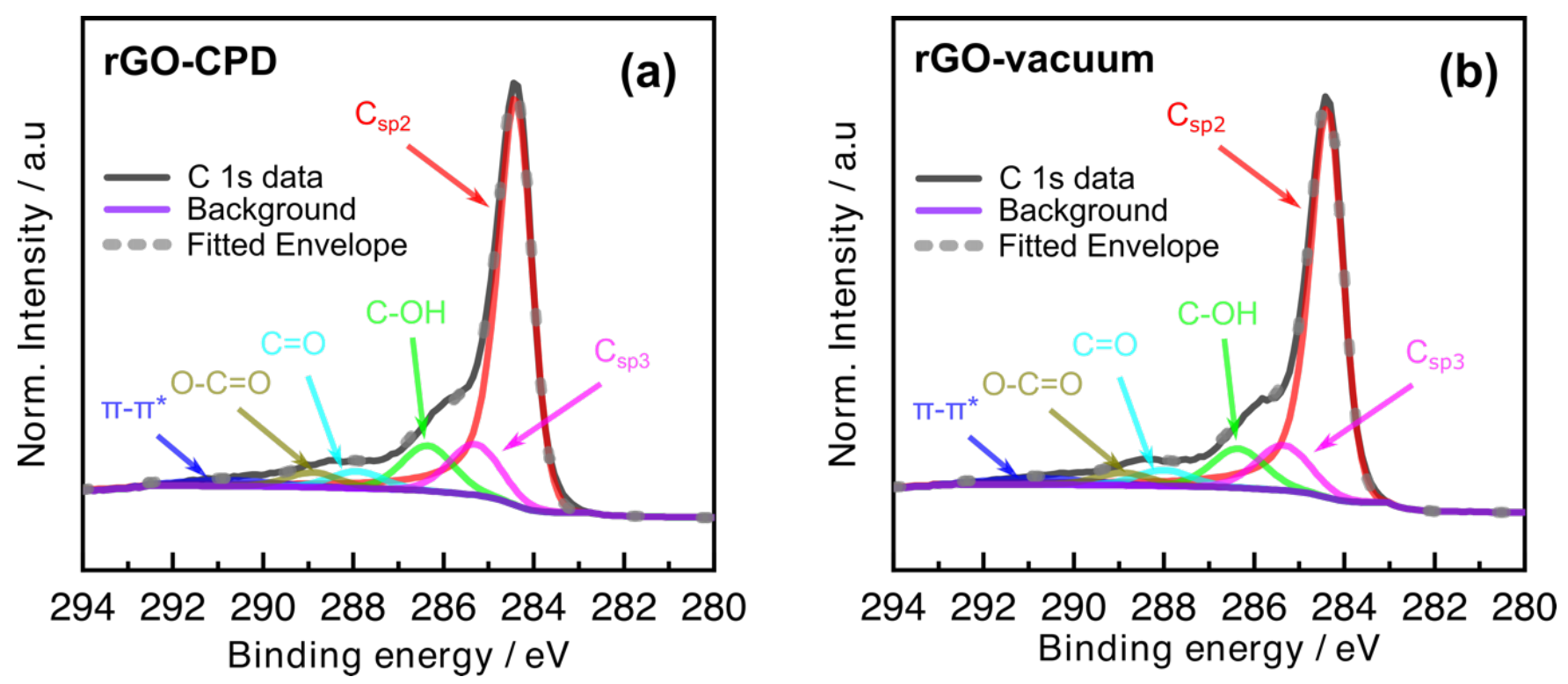

Figure 4. High resolution XPS C1s spectra of (a) rGO-CPD, (b) rGO-vacuum samples. The deconvolution of the $\mathrm{C} 1 \mathrm{~s}$ peak confirms the equivalent chemical identity in the samples.

Given the hypothesized importance of the surface textural characteristics of rGO materials in promoting electrochemical reactions in the VRFB cell, we perform $\mathrm{N}_{2}$ adsorption/desorption measurements to characterize the specific surface area and pore size distribution of the samples (Figure 5). The two isotherms in Figure 5a are type IV, indicating the presence of mesopores (between 2-50 nm), as per the IUPAC classification. ${ }^{[56]}$ However, the isotherms evince significant differences in the total $\mathrm{N}_{2}$ uptake and the shape of the hysteresis loop. The rGO-vacuum display a type $\mathrm{H} 3$ loop at $\mathrm{P} / \mathrm{P}_{0}>0.5$, which is indicative of slit-shaped mesopores. ${ }^{[54,57]}$ In contrast, the rGOCPD show a type $\mathrm{H} 2$ hysteresis response which is indicative of a congruent network of interconnected pores. ${ }^{[54]}$ The rGO-CPD also exhibit an overall BET surface area of $364 \mathrm{~m}^{2} \mathrm{~g}^{-1}$ as compared to $39 \mathrm{~m}^{2} \mathrm{~g}^{-1}$ for the rGO-vacuum. This specific surface area is significantly greater than the previously reported values for hydrothermal $\mathrm{rGO}$, which are typically $<100 \mathrm{~m}^{2} \mathrm{~g}^{-1}$. $^{[54]} \mathrm{We}$ estimate pore size distribution using DFT, assuming slit pore shapes (Figure 5b). From t-plot data (Table 1), both rGO-vacuum and rGO-CPD show pores $<2 \mathrm{~nm}$ in size which account for $\sim 30 \%$ and $\sim 12 \%$ of the total surface area and $\sim 8 \%$ and $\sim 2 \%$ of the total pore volume for rGO-vacuum 
and $\mathrm{rGO}-\mathrm{CPD}$, respectively. In addition to the presence of micropores in the rGO-CPD sample, a wide pore size distribution ranging from $2-90 \mathrm{~nm}$ with a peak at $\sim 20 \mathrm{~nm}$ is evident from differential pore volume, $\mathrm{dV} / \mathrm{d}(\log (\mathrm{D}))\left(\mathrm{cm}^{3} \mathrm{~g}^{-1}\right)$, versus pore width analysis (Figure 5b). Overall, the rGO-CPD appears a mesoporous material with remarkably high surface area and wide pore size distribution as compared to its vacuum-dried counterpart. In the rGO-CPD drying process, the absence of a liquid-gas interface (i.e., surface tension is zero) at the critical point of $\mathrm{CO}_{2}(304.1 \mathrm{~K}$, 7.39 $\mathrm{MPa}$ ) helps to retain the original network of rGO nanosheets, preventing structural collapse, ${ }^{[42]}$ and thus preserving the mesoporous structure and high surface area. Furthermore, the expansion/release of intercalated $\mathrm{CO}_{2}$ promotes layer/nanosheet separation. ${ }^{[54,58]}$ In contrast, vacuum drying leads to structural collapse within the produced materials. Despite these differences, the BET measurements indicate that both of the rGO-deposited samples may provide beneficial added surface area to RFB electrodes. As the two rGO samples are nearly identical in chemical (XPS) and physical (XRD) characteristics but showcase different pore size distribution (BET), we subsequently evaluate the influence of the pore size distributions on electrochemical performance. 

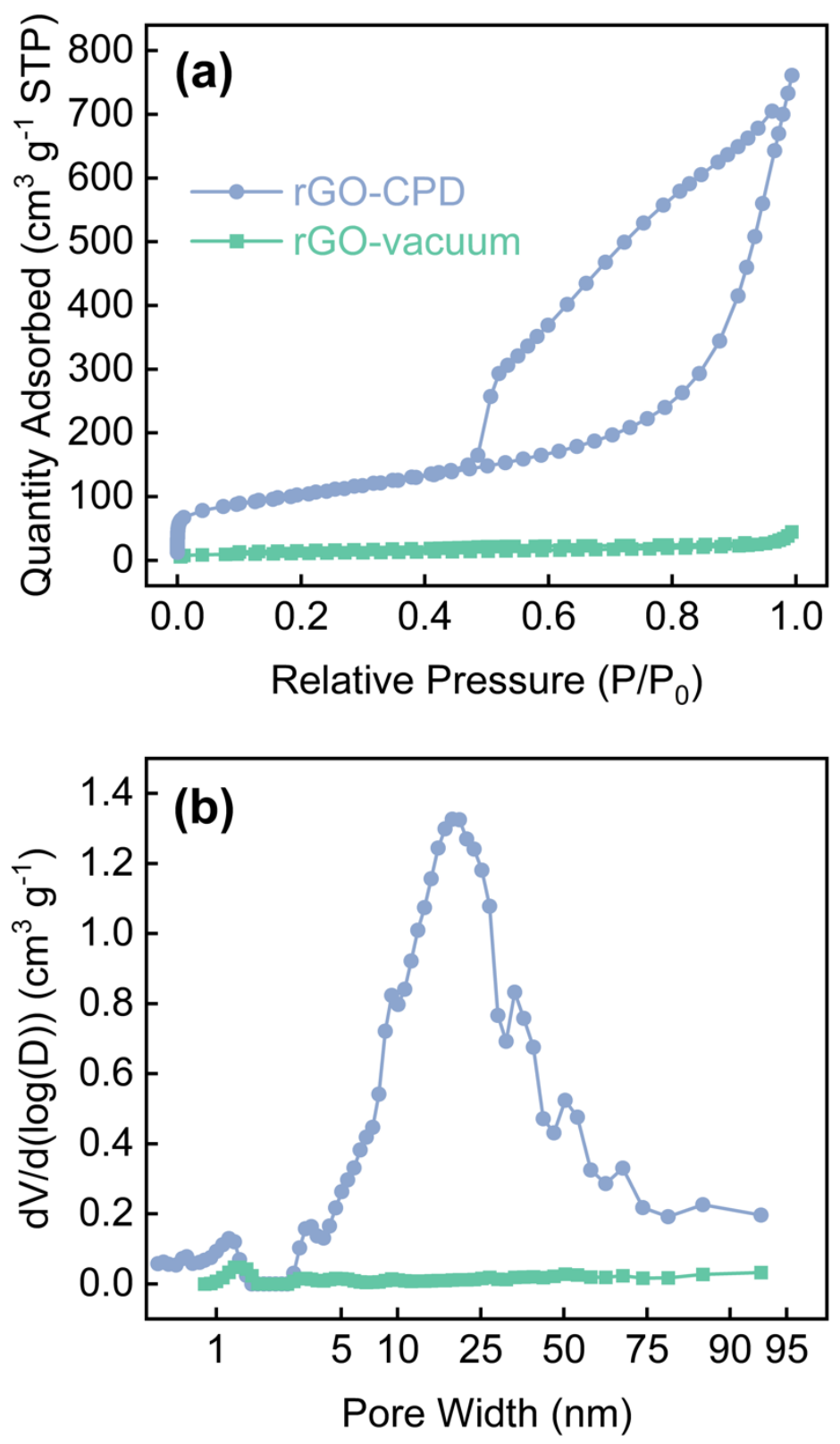

Figure 5. (a) $\mathrm{N}_{2}$ adsorption-desorption isotherms; (b) pore-size distributions for $\mathrm{N}_{2}$ (calculated by using a slit DFT slit model).

Table 1. Specific surface area and pore structure of the rGO materials studied.

\begin{tabular}{|c|c|c|c|c|}
\hline \multirow{2}{*}{ Material } & \multirow{2}{*}{$\begin{array}{c}\text { BET surface } \\
\text { area } \\
\left(\mathrm{m}^{2} \mathrm{~g}^{-1}\right)\end{array}$} & \multirow{2}{*}{$\begin{array}{l}\text { Pore volume } \\
\qquad\left(\mathrm{cm}^{3} \mathrm{~g}^{-1}\right)\end{array}$} & \multicolumn{2}{|c|}{ t-Plot } \\
\hline & & & $\begin{array}{c}\text { Micropore area } \\
\left(m^{2} g^{-1}\right)\end{array}$ & $\begin{array}{c}\text { External surface area } \\
\left(m^{2} g^{-1}\right)\end{array}$ \\
\hline rGO-vacuum & 39 & 0.06 & 11 & 27 \\
\hline rGO-CPD & 364 & 1.17 & 45 & 318 \\
\hline
\end{tabular}




\subsection{Evaluation of $r G O$ in a single VRFB cell}

We evaluate the electrochemical performance of the rGO samples in a VRFB single cell using a binder-free and facile passive flow method. ${ }^{[59]}$ Specifically, we disperse $15 \mathrm{mg}$ of rGO into $3 \mathrm{~mL}$ of DI water, after which we pipette $1.5 \mathrm{~mL}$ of the dispersion into each electrolyte reservoir, and circulate through the corresponding half-cell for 1-2 days; during this time, the rGO particles physically adhere to the carbon felt electrodes, increasing the surface area available for electrochemical reactions. Based on observed changes in the electrolyte color, ${ }^{[34]}$ and because the electrolyte is well-mixed by continuous circulation through the flow cell, we assume the rGO does not settle in the reservoirs; rather, there is a high degree of rGO uptake into the felt electrode. This is also qualitatively supported by SEM images of the rGO-deposited onto the felt (Figure S1). We note that at the estimated loading of $7.5 \mathrm{mg}$ per felt electrode, the lower bound for the total electrode porosity is anticipated to remain unchanged (refer to the Supporting Information for the full derivation). Thus, while clogging is possible at higher microparticle loadings and with thinner, less porous electrodes, we do not anticipate blockage in these small-scale experiments. While this deposition method offers a means of evaluating the impact of rGO microparticles on full cell performance without using binding agents that may convolute subsequent analyses, it can only provide semi-quantitative insights into the structure-property relations of the adhered materials.

First, we compare the performance of pristine felts, pristine felts with deposited rGO-vacuum, and pristine felts with deposited rGO-CPD via discharge polarization and power density curves at $50 \%$ state-of-charge (SOC) (Figure 6a). Examination of Figure 6a shows that the addition of rGO, irrespective of the processing type, reduces cell polarization losses and thus increases achievable power density. The addition of rGO-CPD, however, leads to greater enhancement in 
maximum attainable power density as compared to the addition of rGO-vacuum. Because the electrocatalyst loadings, surface chemistry, and composition are similar between the drying methods, we posit that the difference between the surface area and pore size distribution extracted from $\mathrm{N}_{2}$ adsorption/desorption results in the peak power density differences. To further elucidate the effect of rGO texture and morphology on performance, we conduct electrochemical impedance spectroscopy (EIS) at open-circuit potential for each cell to deconvolute the contribution of ohmic, kinetic, and mass transport resistances. The area-specific ohmic resistances $\left(\mathrm{R}_{\Omega}\right)$ are extracted using the high-frequency intercepts from the Nyquist plots shown in Figure 6b. The ohmic resistance is slightly reduced with the addition of rGO-vacuum $\left(1.28 \Omega \mathrm{cm}^{2}\right)$ and rGO-CPD $(1.09$ $\left.\Omega \mathrm{cm}^{2}\right)$ relative to the pristine felt $\left(1.34 \Omega \mathrm{cm}^{2}\right)$, although these reductions in ohmics may be due to increased electrode wetting because of the longer exposure to aqueous solutions (i.e., multi-day flow deposition procedure). Encouragingly, the magnitude of high-frequency arc corresponding to charge-transfer resistance reduces with the addition of rGO particles regardless of the synthesis route. The relative size of the charge-transfer arc, from largest to smallest, follow the trend of pristine $>$ rGO-vacuum $>$ rGO-CPD. Meanwhile, the low-frequency arc corresponding to the bounded Warburg mass-transfer resistance remains constant for the pristine and rGO-vacuum, with a slight reduction for that of the rGO-CPD. Overall, the EIS results suggest that the increased surface area from the passively deposited rGO benefit charge-transfer by providing additional active sites; further, the higher surface area, mesoporous rGO-CPD leads to decreased chargetransfer resistance as compared to the lower surface area rGO-vacuum. We note that the use of carbon felts of millimeter-scale thicknesses leads to increased cell resistance which, in turn, hampers power performance as compared to thinner electrodes ${ }^{[60]}$ However, the deliberate use of highly porous felts enables microparticle deposition without clogging of the porous structure, 
based on the difference between the estimated felt pore sizes $(\sim 60 \mu \mathrm{m})$ as compared to the typical rGO agglomerate size $(\sim 5-15 \mu \mathrm{m}) .^{[34]}$
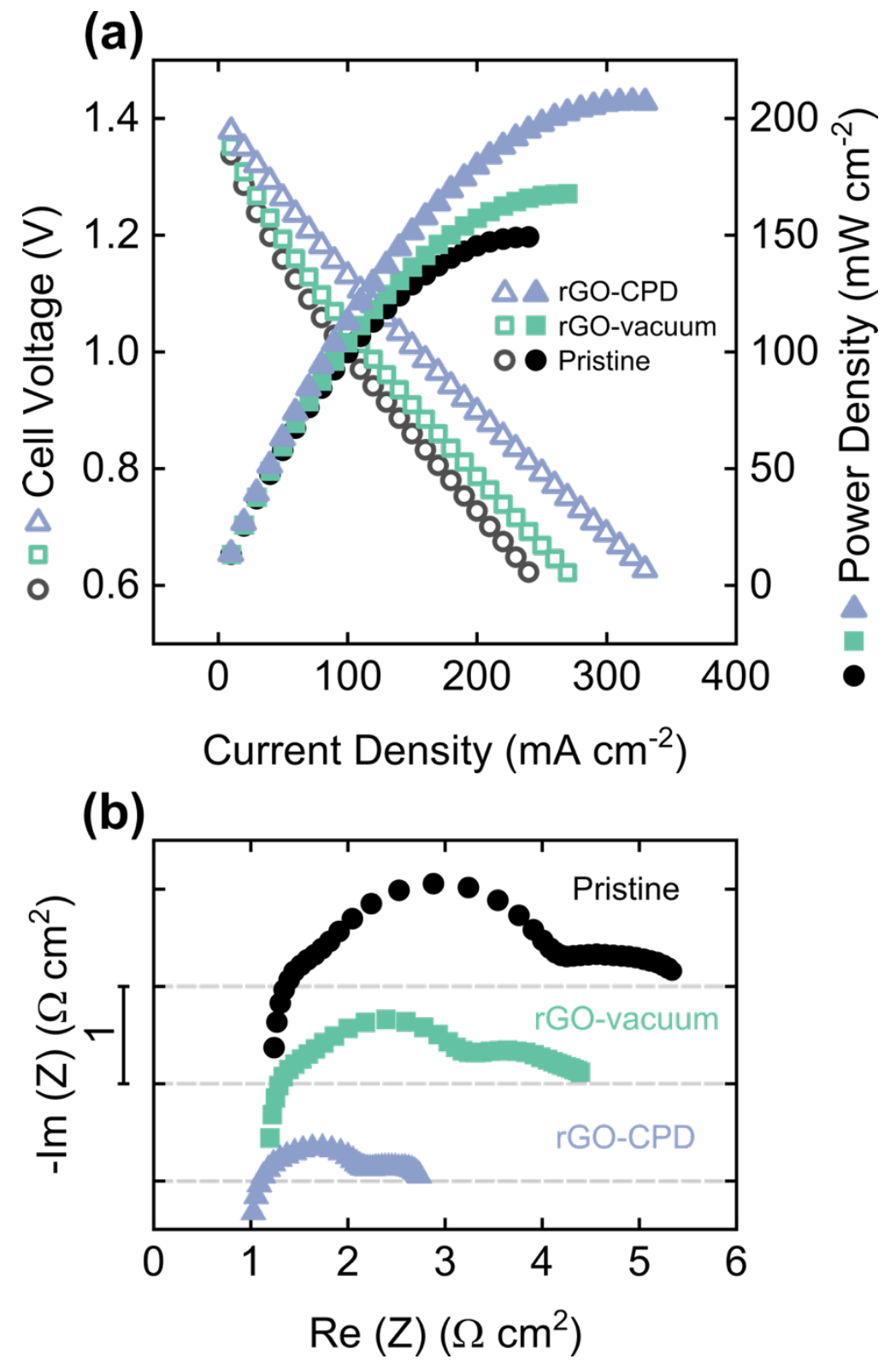

Figure 6. Evaluation of rGO-coated pristine carbon felts in a full-cell VRFB configuration with a starting solution of $1.5 \mathrm{M} \mathrm{V}$ in $2.6 \mathrm{M} \mathrm{H}_{2} \mathrm{SO}_{4}$ charged to $50 \% \mathrm{SOC}$. The volumetric flow rate is 25

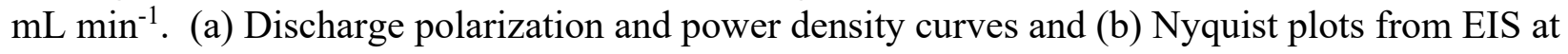
OCV for pristine felt (black circles), rGO-vacuum decorated pristine carbon felt (green circles), and $\mathrm{rGO}-\mathrm{CPD}$ decorated pristine carbon felt (blue triangles). 
As the discharge polarization and EIS results for rGO deposition suggest that $\mathrm{rGO}$ can increase the surface area and reduce charge-transfer resistance in flow cells, we next seek to investigate whether these changes will be as impactful when depositing the better performing rGOCPD onto thermally-activated felts, which possess higher surface area and increased surface functionalization as compared to their pristine counterparts. ${ }^{[61-63]}$ Figure 7a shows the discharge polarization and power density for carbon felt heat-treated at $450{ }^{\circ} \mathrm{C}$ for $6 \mathrm{~h}$ (abbreviated as HT) compared to that of carbon felt heat-treated at $450{ }^{\circ} \mathrm{C}$ for $6 \mathrm{~h}$ and then deposited with rGO-CPD $(\mathrm{HT}+\mathrm{rGO}-\mathrm{CPD})$. The baseline maximum power density for the $\mathrm{HT}$ felt $\left(242 \mathrm{~mW} \mathrm{~cm}{ }^{-2}\right)$ is higher than that of the pristine felt $\left(149 \mathrm{~mW} \mathrm{~cm} \mathrm{~cm}^{-2}\right)$ and exceeds that of the HT + rGO-CPD ( $207 \mathrm{~mW} \mathrm{~cm}^{-2}$ ). Indeed, the addition of rGO-CPD to the heat-treated felt marginally enhances the performance, increasing the peak power density by ca. $9 \mathrm{~mW} \mathrm{~cm}{ }^{-2}$. Nyquist plots of the $\mathrm{HT}$ and $\mathrm{HT}+\mathrm{rGO}-\mathrm{CPD}$ (Figure 7b) corroborate the discharge polarization results. Specifically, the semicircles are similar in shape and appearance, with a slight reduction in size for the higher frequency semicircle corresponding to charge-transfer resistance for the HT + rGO-CPD. Thus, the addition of the rGO-CPD to heat-treated felt leads to incremental improvement by providing active sites in tandem with the higher performing heat-treated felt. Altogether, the results suggest that depositing rGO onto carbon scaffolds can lead to practically realizable benefits for increasing power density through enhanced kinetics, although this effect is more subdued when combined with higher apparent activity scaffolds (i.e., heat-treated felts), leading to diminishing returns on performance. 

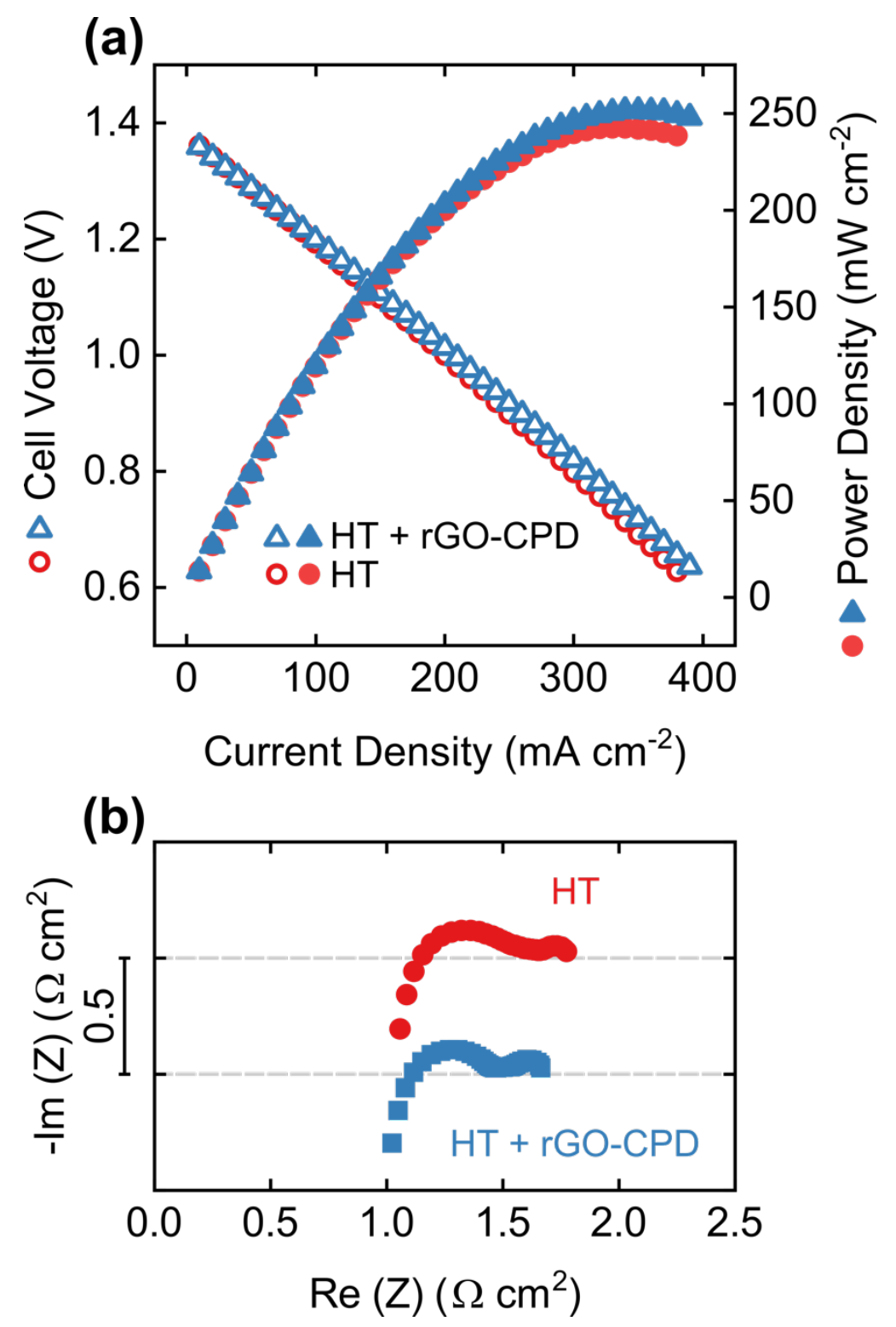

Figure 7. Evaluation of rGO deposited onto carbon-felt heat-treated at $450{ }^{\circ} \mathrm{C}$ for $6 \mathrm{~h}$ in a full-cell VRFB configuration with $1.5 \mathrm{M} \mathrm{V}$ in $2.6 \mathrm{M} \mathrm{H}_{2} \mathrm{SO}_{4}$ charged to $50 \% \mathrm{SOC}$ at a $25 \mathrm{~mL} \mathrm{~min}^{-1}$ flow rate. (a) Discharge polarization and power density curves and (b) Nyquist plots from EIS at OCV for HT felts (red circles) and HT + rGO-CPD (blue squares).

To determine the round-trip efficiency of the best-performing electrode combination, HT + rGO-CPD, we next perform a rate study by galvanostatically cycling at three different current densities $\left(100,150\right.$, and $\left.200 \mathrm{~mA} \mathrm{~cm}^{-2}\right)$, with six charge/discharge cycles per current density. Charge/discharge curves and corresponding efficiencies for the cell are shown in Figure 8. The coulombic efficiency remains relatively consistent throughout the cycling, averaging $94.0 \%$ across 
all cycles. The voltaic efficiency decreases from $78.4 \%$ at $100 \mathrm{~mA} \mathrm{~cm}^{-2}$, to $68.9 \%$ at $150 \mathrm{~mA} \mathrm{~cm}^{-2}$, and $61.1 \%$ at $200 \mathrm{~mA} \mathrm{~cm}^{-2}$. The product of the coulombic and voltaic efficiency yields the energy efficiency, which is $72.7 \%$ at a current density of $100 \mathrm{~mA} \mathrm{~cm}{ }^{-2}$, followed by $65.0 \%$ at 150 $\mathrm{mA} \mathrm{cm}{ }^{-2}$, and $58.1 \%$ at $200 \mathrm{~mA} \mathrm{~cm}{ }^{-2}$. We briefly contextualize the results of the rate study in this work to recent reports of graphene oxide based electrocatalysts in VRFB literature, noting that quantitative comparisons are challenged by differences in operating conditions, choice of cell component materials, and custom flow cell architectures. Park et al. used selectively edgefunctionalized graphene nanoplatelets coated onto carbon felt to achieve an energy efficiency of ca. $69 \%$ at a current density of $150 \mathrm{~mA} \mathrm{~cm}{ }^{-2} \cdot{ }^{[48]} \mathrm{Li}$ et al. leveraged nitrogen-doped graphene oxide modified felt electrodes to attain an energy efficiency of ca. $76 \%$ at a current density of $80 \mathrm{~mA} \mathrm{~cm}{ }^{-2} \cdot{ }^{[64]}$ Abbas et al. synthesized rGO from spent coffee beans, and in a static VRFB cell, reported an energy efficiency of $94 \%$ at a current density of $25 \mathrm{~mA} \mathrm{~cm}{ }^{-2} \cdot{ }^{[43]}$ Overall, the results presented here appear comparable to those reported in prior literature.
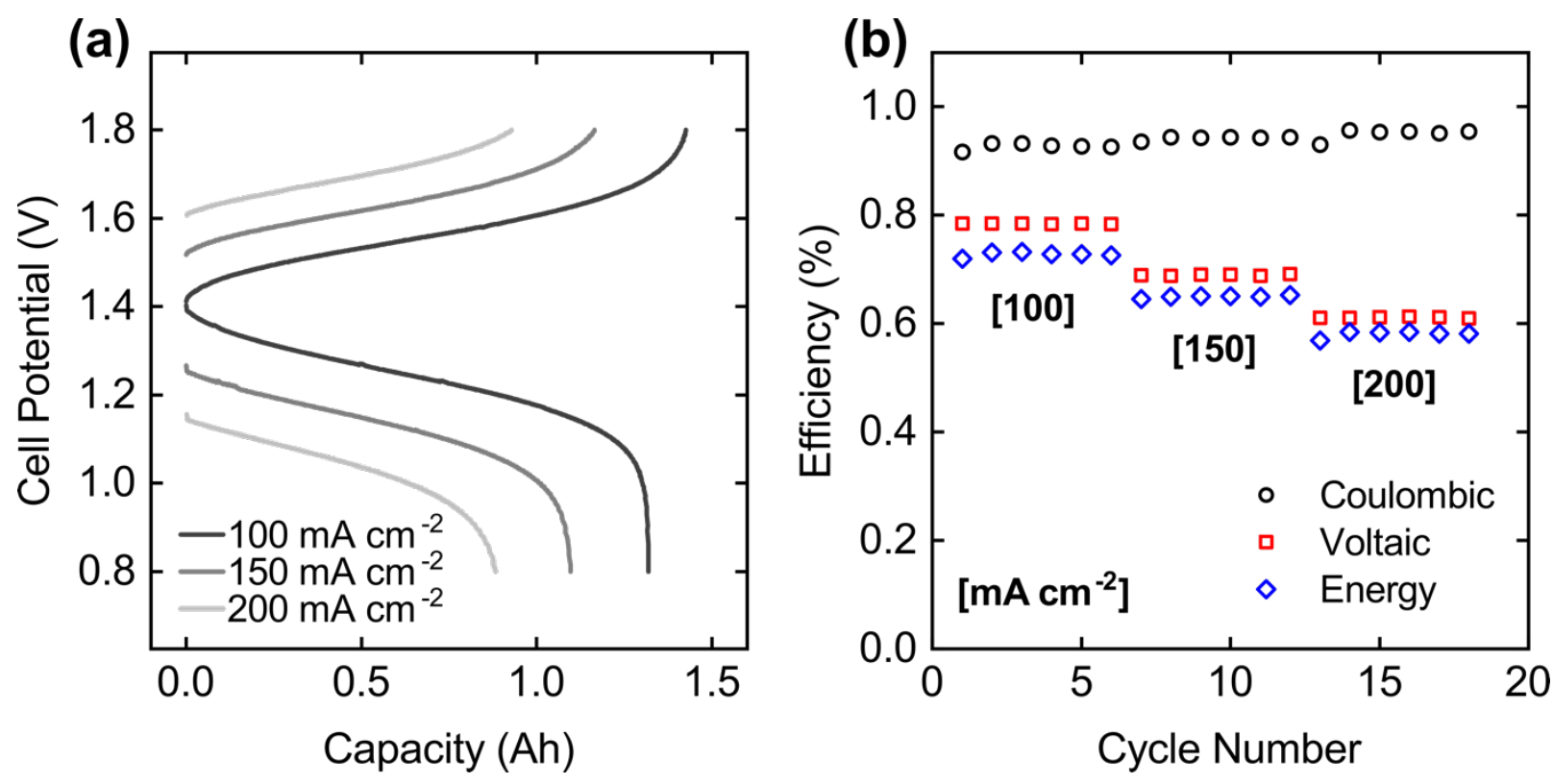

Figure 8. Performance of HT + rGO-CPD electrodes in a VRFB cell at different current densities in $1.5 \mathrm{M} \mathrm{V}$ in $2.6 \mathrm{M} \mathrm{H}_{2} \mathrm{SO}_{4}\left(50 \mathrm{~mL}\right.$ in each reservoir) at a $25 \mathrm{~mL} \mathrm{~min}^{-1}$ flow rate. (a) Voltage vs capacity curves at each current density. The theoretical capacity is $2.01 \mathrm{Ah}$. Data shown are from 
the fifth cycle at each current density. (b) Efficiencies of each cycle (labeled current densities are in $\mathrm{mA} \mathrm{cm}^{-2}$ ).

Among potential sources of concern with the stability of the flow deposition technique over longer durations of cell operation are whether the electrocatalysts remain adhered to the fiber scaffold surface and resist fouling, both of which would reduce the cell performance. To this end, we evaluate the stability of the $\mathrm{HT}+\mathrm{rGO}-\mathrm{CPD}$ by flow cell cycling at a constant current density of $100 \mathrm{~mA} \mathrm{~cm}^{-2}$ for 100 cycles. The efficiencies remain consistent throughout cycling: we achieve average coulombic efficiencies of $94.5 \%$ and voltaic efficiencies of $78.4 \%$, leading to an energy efficiency of $74.1 \%$, with a $2.5 \%$ reduction in energy efficiency from cycle 1 to 100 (Figure 9). The minor reduction in the performance metrics shows that rGO-deposited electrodes can perform reliably over a two-week span of operation.

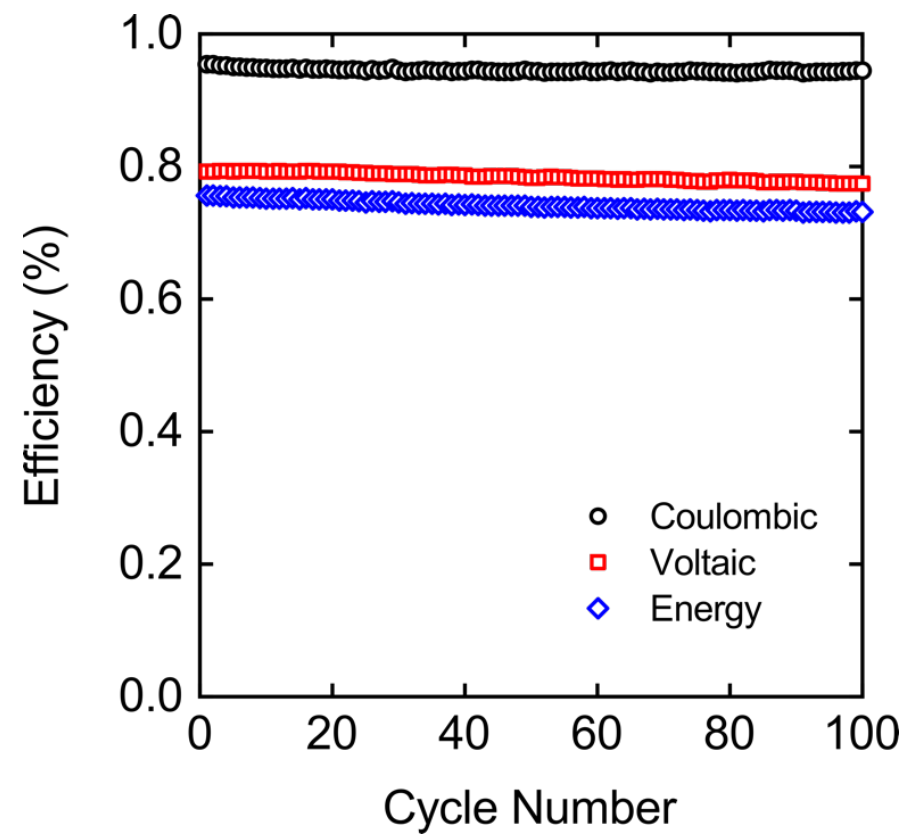

Figure 9. Evolution of the coulombic, voltaic and energy efficiencies of $\mathrm{HT}+\mathrm{rGO}-\mathrm{CPD}$ in $1.0 \mathrm{M}$ $\mathrm{V}$ in $3.0 \mathrm{M} \mathrm{H}_{2} \mathrm{SO}_{4}$ charged to $50 \% \mathrm{SOC}$, with cycling at $100 \mathrm{~mA} \mathrm{~cm}{ }^{-2}$ and a flow rate of $25 \mathrm{~mL}$ $\mathrm{min}^{-1}$. For the 100 cycles shown here, the experiment ran for ca. 12.92 days. 


\section{Conclusions}

High surface area and tunable rGO electrocatalysts deposited onto carbon electrodes provide a method for increasing active sites in RFB electrodes. In this study, we produce rGO microparticles with tunable pore size distribution using a synthetic pathway that is sustainable relative to traditional rGO synthesis methods. We vary the post-synthesis drying method used (i.e., CPD vs vacuum-dried) to produce rGO samples with similar surface chemistry and crystal structure, but profoundly different morphological properties and surface area, thus enabling evaluation of the effect of microparticle mesoporosity and surface area on RFB performance. In particular, the rGOCPD exhibits higher surface and mesoporosity as compared to vacuum drying. We assess the performance of the rGO microparticles in a VRFB single cell through a flow deposition method that is binder-free, facile, and compatible with existing cell architectures. Irrespective of the postsynthesis drying step, flow-deposited rGO onto pristine carbon felts leads to kinetic enhancement, with the mesoporous and higher surface area rGO-CPD exhibiting the highest peak power density improvement. Identifying rGO-CPD as the best performer, we next examine the effect of rGOCPD on heat-treated felts, combining the addition of rGO with a commonly used electrode pretreatment methodology. The deposition of rGO-CPD onto heat-treated carbon felts leads to less marked improvement in power density, although kinetics are slightly enhanced, suggesting that further electrocatalyst optimization will be necessary when combining high surface area microparticles with a thermally activated scaffold. These results are relevant for carbon engineering efforts for designing textured microparticles that enhance performance in macroporous scaffolds. 


\section{Acknowledgements}

A.A. gratefully acknowledges support from the KACST-MIT Ibn Khaldun Fellowship for Saudi Arabian Women. Research by C.T.W. and F.R.B. was supported by the Joint Center for Energy Storage Research (JCESR), an Energy Innovation Hub funded by the U.S. Department of Energy, Office of Science, Basic Energy Sciences. C.T.W. acknowledges a graduate fellowship through the National Science Foundation Graduate Research Fellowship Program under Grant No. 1122374. Any opinions, findings, and conclusions or recommendations expressed in this material are those of the authors and do not necessarily reflect the views of the National Science Foundation. The authors thank Christopher Mallia, Bertrand Neyhouse, and Katelyn Ripley for their insightful feedback on the manuscript. Finally, this manuscript makes use of equipment in MIT's Center for Materials Science and Engineering Shared Experimental Facilities, supported in part by the MRSEC Program of the National Science Foundation under award number DMR1419807.

\section{CRediT authorship contribution statement}

Amira Alazmi: Conceptualization, Methodology, Validation, Formal analysis, Investigation, Data Curation, Writing - Original Draft, Writing - Review \& Editing, Visualization. Charles TaiChieh Wan: Conceptualization, Methodology, Validation, Formal analysis, Investigation, Data Curation, Writing - Original Draft, Writing - Review \& Editing, Visualization. Pedro M. F. J.

Costa: Funding, Resources. Fikile R. Brushett: Funding, Resources, Writing - Review \& Editing, Project Administration, Supervision. 


\section{References}

[1]. Carrasco, J. M.; Franquelo, L. G.; Bialasiewicz, J. T.; Galvan, E.; PortilloGuisado, R. C.; Prats, M. A. M.; Leon, J. I.; Moreno-Alfonso, N., Power-Electronic Systems for the Grid Integration of Renewable Energy Sources: A Survey. IEEE Transactions on Industrial Electronics 2006, 53 (4), 1002-1016.

[2]. Liserre, M.; Sauter, T.; Hung, J. Y., Future Energy Systems: Integrating Renewable Energy Sources into the Smart Power Grid Through Industrial Electronics. IEEE Industrial Electronics Magazine 2010, 4 (1), 18-37.

[3]. Fu, Q.; Montoya, L. F.; Solanki, A.; Nasiri, A.; Bhavaraju, V.; Abdallah, T.; Yu, D. C., Microgrid Generation Capacity Design With Renewables and Energy Storage Addressing Power Quality and Surety. IEEE Transactions on Smart Grid 2012, 3 (4), 2019-2027.

[4]. Liang, X., Emerging Power Quality Challenges Due to Integration of Renewable Energy Sources. ieee transactions on industry applications 2017, 53 (2), 855-866.

[5]. Tsai, H.-M.; Yang, S.-J.; Ma, C.-C. M.; Xie, X., Preparation and electrochemical activities of iridium-decorated graphene as the electrode for all-vanadium redox flow batteries. Electrochimica Acta 2012, 77, 232-236.

[6]. Moghim, M. H.; Eqra, R.; Babaiee, M.; Zarei-Jelyani, M.; Loghavi, M. M., Role of reduced graphene oxide as nano-electrocatalyst in carbon felt electrode of vanadium redox flow battery. Journal of Electroanalytical Chemistry 2017, 789, 67-75.

[7]. Minke, C.; Turek, T., Materials, system designs and modelling approaches in technoeconomic assessment of all-vanadium redox flow batteries - A review. Journal of Power Sources 2018, 376, 66-81.

[8]. Kausar, N.; Mousa, A.; Skyllas-Kazacos, M., The Effect of Additives on the HighTemperature Stability of the Vanadium Redox Flow Battery Positive Electrolytes.

ChemElectroChem 2016, 3 (2), 276-282.

[9]. Park, J. H.; Park, J. J.; Lee, H. J.; Min, B. S.; Yang, J. H., Influence of Metal Impurities or Additives in the Electrolyte of a Vanadium Redox Flow Battery. Journal of The Electrochemical Society 2018, 165 (7), A1263-A1268.

[10]. Xia, L.; Zhang, Q.; Wu, C.; Liu, Y.; Ding, M.; Ye, J.; Cheng, Y.; Jia, C., Graphene coated carbon felt as a high-performance electrode for all vanadium redox flow batteries. Surface and Coatings Technology 2019, 358, 153-158.

[11]. Wan, C. T.-C.; López Barreiro, D.; Forner-Cuenca, A.; Barotta, J.-W.; Hawker, M. J.; Han, G.; Loh, H.-C.; Masic, A.; Kaplan, D. L.; Chiang, Y.-M., Exploration of Biomass-Derived Activated Carbons for Use in Vanadium Redox Flow Batteries. ACS Sustainable Chemistry \& Engineering 2020, 8 (25), 9472-9482.

[12]. Li, W.; Liu, J.; Yan, C., Reduced graphene oxide with tunable C/O ratio and its activity towards vanadium redox pairs for an all vanadium redox flow battery. Carbon 2013, 55, 313320.

[13]. González, Z.; Flox, C.; Blanco, C.; Granda, M.; Morante, J. R.; Menéndez, R.; Santamaría, R., Outstanding electrochemical performance of a graphene-modified graphite felt for vanadium redox flow battery application. Journal of Power Sources 2017, 338, 155-162. [14]. Waters, S. E.; Robb, B. H.; Marshak, M. P., Effect of Chelation on Iron-Chromium Redox Flow Batteries. ACS Energy Letters 2020, 5 (6), 1758-1762. 
[15]. Houser, J.; Clement, J.; Pezeshki, A.; Mench, M. M., Influence of architecture and material properties on vanadium redox flow battery performance. Journal of Power Sources 2016, 302, 369-377.

[16]. Menictas, C.; Skyllas-Kazacos, M., Performance of vanadium-oxygen redox fuel cell. Journal of Applied Electrochemistry 2011, 41 (10), 1223.

[17]. Ferrigno, R.; Stroock, A. D.; Clark, T. D.; Mayer, M.; Whitesides, G. M., Membraneless Vanadium Redox Fuel Cell Using Laminar Flow. Journal of the American Chemical Society 2002, 124 (44), 12930-12931.

[18]. Gurieff, N.; Cheung, C. Y.; Timchenko, V.; Menictas, C., Performance enhancing stack geometry concepts for redox flow battery systems with flow through electrodes. Journal of Energy Storage 2019, 22, 219-227.

[19]. Percin, K.; Rommerskirchen, A.; Sengpiel, R.; Gendel, Y.; Wessling, M., 3D-printed conductive static mixers enable all-vanadium redox flow battery using slurry electrodes. Journal of Power Sources 2018, 379, 228-233.

[20]. Kim, K. J.; Park, M.-S.; Kim, Y.-J.; Kim, J. H.; Dou, S. X.; Skyllas-Kazacos, M., A technology review of electrodes and reaction mechanisms in vanadium redox flow batteries. Journal of Materials Chemistry A 2015, 3 (33), 16913-16933.

[21]. Zhong, S.; Padeste, C.; Kazacos, M.; Skyllas-Kazacos, M., Comparison of the physical, chemical and electrochemical properties of rayon- and polyacrylonitrile-based graphite felt electrodes. Journal of Power Sources 1993, 45 (1), 29-41.

[22]. Sun, B.; Skyllas-Kazacos, M., Modification of graphite electrode materials for vanadium redox flow battery application-I. Thermal treatment. Electrochimica Acta 1992, 37 (7), 12531260 .

[23]. Zhang, W.; Xi, J.; Li, Z.; Zhou, H.; Liu, L.; Wu, Z.; Qiu, X., Electrochemical activation of graphite felt electrode for $\mathrm{VO} 2+/ \mathrm{VO} 2+$ redox couple application. Electrochimica Acta 2013, $89,429-435$.

[24]. Sun, B.; Skyllas-Kazacos, M., Chemical modification of graphite electrode materials for vanadium redox flow battery application-part II. Acid treatments. Electrochimica Acta 1992, 37 (13), 2459-2465.

[25]. Yue, L.; Li, W.; Sun, F.; Zhao, L.; Xing, L., Highly hydroxylated carbon fibres as electrode materials of all-vanadium redox flow battery. Carbon 2010, 48 (11), 3079-3090. [26]. Roznyatovskaya, N.; Noack, J.; Pinkwart, K.; Tübke, J., Aspects of electron transfer processes in vanadium redox-flow batteries. Current Opinion in Electrochemistry 2020, 19, 4248 .

[27]. Wu, X.; Xu, H.; Xu, P.; Shen, Y.; Lu, L.; Shi, J.; Fu, J.; Zhao, H., Microwave-treated graphite felt as the positive electrode for all-vanadium redox flow battery. Journal of Power Sources 2014, 263, 104-109.

[28]. Rychcik, M.; Skyllas-Kazacos, M., Evaluation of electrode materials for vanadium redox cell. Journal of Power Sources 1987, 19 (1), 45-54.

[29]. Di Blasi, A.; Di Blasi, O.; Briguglio, N.; Aricò, A. S.; Sebastián, D.; Lázaro, M. J.; Monforte, G.; Antonucci, V., Investigation of several graphite-based electrodes for vanadium redox flow cell. Journal of Power Sources 2013, 227, 15-23.

[30]. Chen, J.-Z.; Liao, W.-Y.; Hsieh, W.-Y.; Hsu, C.-C.; Chen, Y.-S., All-vanadium redox flow batteries with graphite felt electrodes treated by atmospheric pressure plasma jets. Journal of Power Sources 2015, 274, 894-898. 
[31]. Li, X.-g.; Huang, K.-1.; Liu, S.-q.; Tan, N.; Chen, L.-q., Characteristics of graphite felt electrode electrochemically oxidized for vanadium redox battery application. Transactions of Nonferrous Metals Society of China 2007, 17 (1), 195-199.

[32]. Amini, K.; Gostick, J.; Pritzker, M. D., Metal and Metal Oxide Electrocatalysts for Redox Flow Batteries. Advanced Functional Materials 2020, 30 (23), 1910564.

[33]. Aaron, D.; Yeom, S.; Kihm, K. D.; Ashraf Gandomi, Y.; Ertugrul, T.; Mench, M. M., Kinetic enhancement via passive deposition of carbon-based nanomaterials in vanadium redox flow batteries. Journal of Power Sources 2017, 366, 241-248.

[34]. Wan, C. T.-C.; López Barreiro, D.; Forner-Cuenca, A.; Barotta, J.-W.; Hawker, M. J.; Han, G.; Loh, H.-C.; Masic, A.; Kaplan, D. L.; Chiang, Y.-M.; Brushett, F. R.; Martin-Martinez, F. J.; Buehler, M. J., Exploration of Biomass-Derived Activated Carbons for Use in Vanadium Redox Flow Batteries. ACS Sustainable Chemistry \& Engineering 2020, 8 (25), 9472-9482. [35]. Heydari Gharahcheshmeh, M.; Wan, C. T.-C.; Ashraf Gandomi, Y.; Greco, K. V.; Forner-Cuenca, A.; Chiang, Y.-M.; Brushett, F. R.; Gleason, K. K., Ultrathin Conformal oCVD PEDOT Coatings on Carbon Electrodes Enable Improved Performance of Redox Flow Batteries. Advanced Materials Interfaces 2020, 7 (20), 2000855.

[36]. Yang, D.-S.; Han, J. H.; Jeon, J. W.; Lee, J. Y.; Kim, D.-G.; Seo, D. H.; Kim, B. G.; Kim, T.-H.; Hong, Y. T., Multimodal porous and nitrogen-functionalized electrode based on graphite felt modified with carbonized porous polymer skin layer for all-vanadium redox flow battery. Materials Today Energy 2019, 11, 159-165.

[37]. Zhang, X.; Wu, Q.; Lv, Y.; Li, Y.; Zhou, X., Binder-free carbon nano-network wrapped carbon felt with optimized heteroatom doping for vanadium redox flow batteries. Journal of Materials Chemistry A 2019, 7 (43), 25132-25141.

[38]. Sun, J.; Jiang, H. R.; Wu, M. C.; Fan, X. Z.; Chao, C. Y. H.; Zhao, T. S., Aligned hierarchical electrodes for high-performance aqueous redox flow battery. Applied Energy 2020, $271,115235$.

[39]. Chen, D.; Tang, L.; Li, J., Graphene-based materials in electrochemistry. Chemical Society Reviews 2010, 39 (8), 3157-3180.

[40]. Alazmi, A.; Rasul, S.; Patole, S. P.; Costa, P. M., Comparative study of synthesis and reduction methods for graphene oxide. Polyhedron 2016, 116, 153-161.

[41]. Rasul, S.; Alazmi, A.; Jaouen, K.; Hedhili, M. N.; Costa, P., Rational design of reduced graphene oxide for superior performance of supercapacitor electrodes. Carbon 2017, 111, 774781.

[42]. Alazmi, A.; El Tall, O.; Hedhili, M. N.; Costa, P. M., The impact of surface chemistry and texture on the CO2 uptake capacity of graphene oxide. Inorganica Chimica Acta 2018, 482, 470-477.

[43]. Abbas, A.; Eng, X. E.; Ee, N.; Saleem, F.; Wu, D.; Chen, W.; Handayani, M.; Tabish, T. A.; Wai, N.; Lim, T. M., Development of reduced graphene oxide from biowaste as an electrode material for vanadium redox flow battery. Journal of Energy Storage 2021, 41, 102848.

[44]. Pan, M.; Zhang, Y.; Shan, C.; Zhang, X.; Gao, G.; Pan, B., Flat graphene-enhanced electron transfer involved in redox reactions. Environmental science \& technology 2017, 51 (15), 8597-8605.

[45]. Wang, J.; Gan, L.; Zhang, W.; Peng, Y.; Yu, H.; Yan, Q.; Xia, X.; Wang, X., In situ formation of molecular Ni-Fe active sites on heteroatom-doped graphene as a heterogeneous electrocatalyst toward oxygen evolution. Science Advances 2018, 4 (3), eaap7970. 
[46]. Park, M.; Ryu, J.; Cho, J., Nanostructured Electrocatalysts for All-Vanadium Redox Flow Batteries. Chemistry - An Asian Journal 2015, 10 (10), 2096-2110.

[47]. Bayeh, A. W.; Kabtamu, D. M.; Chang, Y.-C.; Chen, G.-C.; Chen, H.-Y.; Lin, G.-Y.; Liu, T.-R.; Wondimu, T. H.; Wang, K.-C.; Wang, C.-H., Synergistic effects of a TiNb2O7reduced graphene oxide nanocomposite electrocatalyst for high-performance all-vanadium redox flow batteries. Journal of Materials Chemistry A 2018, 6 (28), 13908-13917.

[48]. Park, M.; Jeon, I.-Y.; Ryu, J.; Baek, J.-B.; Cho, J., Exploration of the Effective Location of Surface Oxygen Defects in Graphene-Based Electrocatalysts for All-Vanadium Redox-Flow Batteries. Advanced Energy Materials 2015, 5 (5), 1401550.

[49]. Han, P.; Wang, H.; Liu, Z.; Chen, X.; Ma, W.; Yao, J.; Zhu, Y.; Cui, G., Graphene oxide nanoplatelets as excellent electrochemical active materials for $\mathrm{VO} 2+/ \mathrm{VO} 2+$ and $\mathrm{V} 2+/ \mathrm{V} 3+$ redox couples for a vanadium redox flow battery. Carbon 2011, 49 (2), 693-700.

[50]. Nia, P. M.; Abouzari-Lotf, E.; Woi, P. M.; Alias, Y.; Ting, T. M.; Ahmad, A.; Che Jusoh, N. W., Electrodeposited reduced graphene oxide as a highly efficient and low-cost electrocatalyst for vanadium redox flow batteries. Electrochimica Acta 2019, 297, 31-39. [51]. Anantha, M. S.; Anarghya, D.; Hu, C.; Reddy, N.; Venkatesh, K.; Muralidhara, H. B., Electrochemical performance of graphene oxide modified graphite felt as a positive electrode in all-iron redox flow batteries. Journal of Applied Electrochemistry 2021, 51 (2), 331-344. [52]. Marcano, D. C.; Kosynkin, D. V.; Berlin, J. M.; Sinitskii, A.; Sun, Z.; Slesarev, A.; Alemany, L. B.; Lu, W.; Tour, J. M., Improved synthesis of graphene oxide. ACS nano 2010, 4 (8), 4806-4814.

[53]. Alazmi, A.; El Tall, O.; Rasul, S.; Hedhili, M. N.; Patole, S. P.; Costa, P. M., A process to enhance the specific surface area and capacitance of hydrothermally reduced graphene oxide. Nanoscale 2016, 8 (41), 17782-17787.

[54]. Alazmi, A.; El Tall, O.; Rasul, S.; Hedhili, M. N.; Patole, S. P.; Costa, P. M. F. J., A process to enhance the specific surface area and capacitance of hydrothermally reduced graphene oxide. Nanoscale 2016, 8 (41), 17782-17787.

[55]. Milshtein, J. D., Electrochemical engineering of low-cost and high-power redox flow batteries. 2017.

[56]. Sing, K. S. W., Reporting physisorption data for gas/solid systems with special reference to the determination of surface area and porosity (Recommendations 1984). Pure and Applied Chemistry 1985, 57 (4), 603-619.

[57]. Ramimoghadam, D.; Hussein, M. Z. B.; Taufiq-Yap, Y. H., Hydrothermal synthesis of zinc oxide nanoparticles using rice as soft biotemplate. Chemistry Central Journal 2013, 7 (1), 136.

[58]. Feng, X., Nanocarbons for Advanced Energy Storage, Volume 1. Wiley: 2015.

[59]. Aaron, D.; Yeom, S.; Kihm, K. D.; Ashraf Gandomi, Y.; Ertugrul, T.; Mench, M. M. [60]. Aaron, D. S.; Liu, Q.; Tang, Z.; Grim, G. M.; Papandrew, A. B.; Turhan, A.; Zawodzinski, T. A.; Mench, M. M., Dramatic performance gains in vanadium redox flow batteries through modified cell architecture. Journal of Power Sources 2012, 206, 450-453. [61]. Sun, B.; Skyllas-Kazacos, M.

[62]. Pezeshki, A. M.; Clement, J. T.; Veith, G. M.; Zawodzinski, T. A.; Mench, M. M., High performance electrodes in vanadium redox flow batteries through oxygen-enriched thermal activation. Journal of Power Sources 2015, 294, 333-338. 
[63]. Greco, K. V.; Forner-Cuenca, A.; Mularczyk, A.; Eller, J.; Brushett, F. R., Elucidating the Nuanced Effects of Thermal Pretreatment on Carbon Paper Electrodes for Vanadium Redox Flow Batteries. ACS Applied Materials \& Interfaces 2018, 10 (51), 44430-44442.

[64]. Li, Q.; Liu, J.; Bai, A.; Li, P.; Li, J.; Zhang, X.; Yu, M.; Wang, J.; Sun, H., Preparation of a Nitrogen-Doped Reduced Graphene Oxide-Modified Graphite Felt Electrode for $\mathrm{VO}^{2+} / \mathrm{VO}_{2}{ }^{+}$ Reaction by Freeze-Drying and Pyrolysis Method. Journal of Chemistry 2019, 2019, 8958946. 